\title{
AUTOMATION OF SHEET METAL COMBINATION DIE DESIGN PROCESS
}

\author{
Hussein M.A. Hussein ${ }^{1}$, Hossam Salem ${ }^{1}$, Walla Abdelzaher ${ }^{1}$, Vishal Naranje $^{2}$, Morcos I. \\ Ghobrial $^{1}$, Azza Barakat ${ }^{1}$
}

\author{
${ }^{1}$ Mechanical Engineering Dept., Faculty of Engineering, Helwan University, 11732 Cairo, Egypt \\ ${ }^{2}$ Mechanical Engineering Department, Amity University Dubai, 345019 UAE
}

Corresponding author: Hussein M.A. Hussein, hussein@h-eng.helwan.edu.eg

\begin{abstract}
This paper proposed a novel methodology for designing and manufacturing of sheet metal dies based on features of sheet parts. Also, combination is designed according to die cupping and punching features of sheet metal parts. The proposed approach is an attempt to make seamless integration of computer aided design with computer aided manufacturing. The features used in this study are taken from MusumiTM Catalogue as well as from various small and medium scale sheet metal industries. Work is divided into two phases. In the first phase, the relevant geometrical and topological data is extracted by reading STEP AP 203. In the second phase, a combine adjacency matrix and rule-based system is developed to recognize sheet metal features for die manufacturing. The system showed excellent performance for all types of features contained in the MusumiTM catalog and for different sheet metal industries

The proposed system for automated design of combination dies for sheet metal parts has been tested successfully for various types of industrial deep drawn parts. It reduces the die compoment design time from hours to minutes. selection of die components and drawings generated by the system were found to be reasonable and very similar to those actually used in the sheet metal industries for production of these typical components on combination dies.
\end{abstract}

Key words: Sheet metal, Feature Recognition, Cupping and punching, Die-Type, Combination Die.

\section{INTRODUCTION}

Sheet metal components are widely used in a variety of industrial applications and are integral parts of many industrial products due to their ability to form into a variety of shapes. These shapes can be classified into different features. These shapes can be classified according to their features. Each sheet metal feature can also be used to represent manufacturing information of the variety of single die or Progressive die. Different die manufacturing domains required different feature representations resulting in a more efficient die design process. Because the features used to design the sheet metal part do not always represent the best way to manufacture the sheet metal. Hence there is an efficient integrated system is needed which will define the design feature that can be converted into manufacturing feature of the sheet metal die.

Recently number of sheet metal tooling design software are available in market, but most of available sheet metal modeling software are failed to integrate with CAM system available in this field. Therefore, concurrent engineering approach is missing in the sheet metal die design process [1]. The major limitation for seamless integration between $\mathrm{CAD}$ and CAM is to problem in defining the various types of sheet metal features into a standard format. The objective of this research is to develop a novel methodology for Feature Recognition for manufacturing support of sheet metal die design at the preliminary design cycle. A system has been proposed to automatically extract common 2D/3D internal as well as forming sheet metal features from STEP AP203 files. The features used in this study are taken from MusumiTM Catalogue as well as from various small and medium scale sheet metal industries. In the first phase, the relevant geometrical and topological data is extracted by reading STEP AP 203 file using a computer program made entirely in Visual basic programming language. Afterwards, algorithms are applied to identify feature loop and define edge taxonomy. In the second phase, rule-based system is developed to recognize different sheet metal features and integrate these features with die design process. The software first does a check on possible features that could be present in the model and then uses rules system to identify the feature. The system works well for all types of features contained in the MusumiTM catalog and for different sheet metal industries. Since the extracted features include geometry and engineering information, they will be effective use in development manufacturability check and cost estimation of sheet metal parts. The Feature recognition process is demonstrated using a range of typical sheet metal industrial components as shown in Figure 1. 

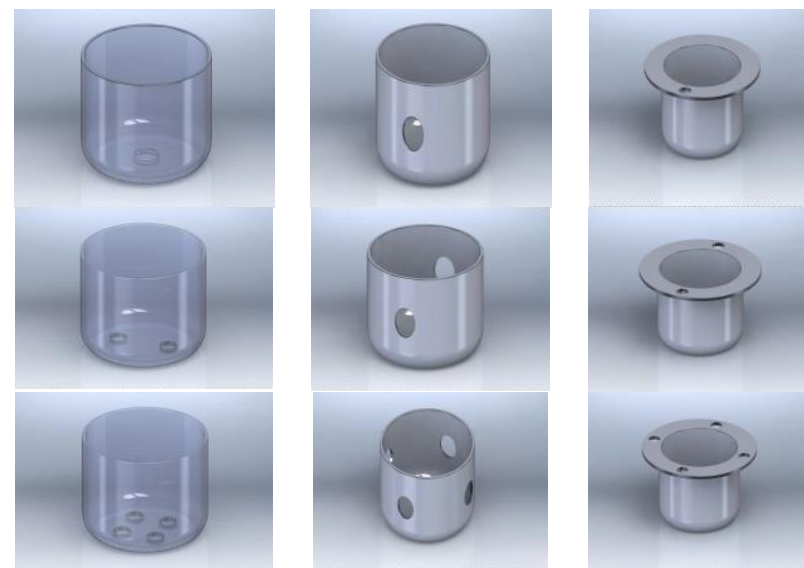

Fig.1. Some typical cupping and punching sheet metal parts

In general, most of the sheet metal parts are either manufactured using forming process or using cutting dies, in the paper, emphasis is given on sheet metal parts manufactured using combination die. In the industry, selection, and design of die components is time consuming and tedious task. Each type of die need a specific number of die components; these components are determine using theoretical calculations as well as on the basis of experience. But in actual practice scenario of die design, minor or major changes happen in selection/design off die components. Also, as per process planning calculation, it leads to a single die type, but in real world situation it may found that multi sequence die types is required [2]. Hence there is need of the system which will efficiently transfer the sheet metal features to die design process in order to reduce die design time and efforts. There are many die types could be found in industrial applications such as blanking, punching, bending, drawing, progressive, compound and combination dies.

In this paper, the feature recognition technique via STEP file is used for designing a combination die for cupping and piercing from sheet metal features. Few researchers used feature recognition for combination die type design for combined cupping and punching operations [3]-[4]. The proposed integrated system, recognized the sheet metal part features, Cup in 3D and the shape of punches profiles in $2 \mathrm{D}$. The system selects the proper dietype design, which is stored in the program code library, then draw the suitable combination die using developed system on SolidWorks software.

\section{FEATURE RECOGNITION TECHNIQUE}

In the proposed work first, the 3D Solid model is created and represented as part design. The solid model of the part design consists of small and different solid primitives combined together to form the required part design. The geometrical information of solid model is stored in STEP AP 203 file [6]. Using a suitable feature extraction algorithm sheet metal features stored in this STEP file are extracted. Algorithm coded in visual basic programming language and excel. First, the developed feature extraction algorithm reads the STEP file and Identifies all existing surfaces and their types. After identifications of the features of sheet metal part, the sheet metal part dimensions and engineering information are extracted and stored in a database. The second stage is to use this engineering information for selection of appropriate type of sheet metal operation to produce the identified sheet metal features. This information can be used to design a suitable type of die. The various selection of proper type and size of various die components including die block, die gages, stripper, stripper plate, punch(es), punch plate, back plate, blankholder, die set and fasteners are carried out after making a set of mathematical operations and establishing the relationships between different die components.

The sheet metal features could be simply classified as 2D features as in Figure 2, and 3-dimension features as shown in Figure 3. The features used in this study are taken from MusumiTM Catalogue [7]. To define the each, feature a separate rule has been formed. The rules are based on the hierarchy structure of data extraction file. There is a Conditions is defined for specific feature recognition.

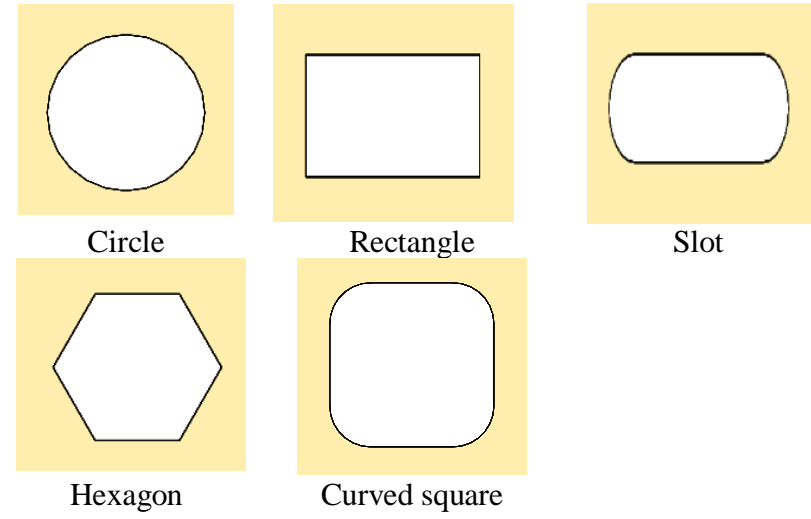

Fig. 2. Sample from 2D punching features
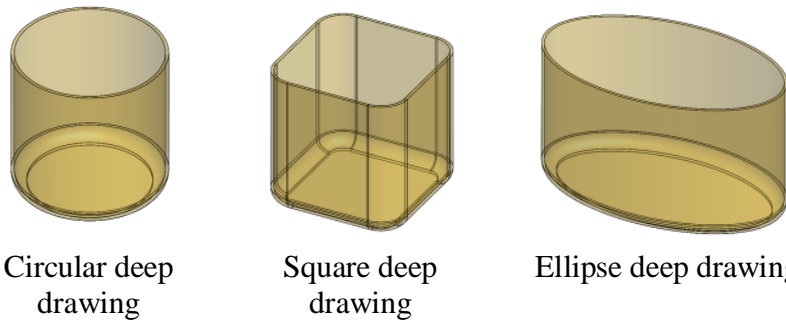

Ellipse deep drawing

Fig. 3. Sample from 3D drawing features

Table 1 illustrates a sample of rules prepared to recognize the 2D punching features. The rules are arranged using of Rule Based Reasoning technique, 
the "IF-Then" rules for development of feature recognition plan. Table 1 describes some rules used for defining 2D features, the circle and the square with round corners. In the proposed system various features such triangle, square, circle, rectangle, pentagon, hexagon etc. are defined using the Rule Based Reasoning technique. Till now total cover 49 punching features have been collected from MusumiTM catalogue are defined.

The rules are designed according to the number of edges, vertices, surfaces which extracted from the part data-base. Similar rules are designed to recognize the 3D features. Table 2 illustrate the rules designed to recognize the $3 \mathrm{D}$ features as in cupping and drawing features. Most of this rule depends on surfaces and faces. The features recognition routine is made to check the STEP natural file line by line. The algorithm first check if the part is open shell of closed shell, if part is open shell, then it works with free form surface, if part is closed shell, then it works with sheet metal with a thickness or any other volumetric body. Figure 4 shows a simple flowchart for both of punched and cupping features and the designed sequence to recognize the features inside.

Table 1. Conditions for feature recognition (Punching feature)

\begin{tabular}{|c|c|}
\hline IF & Then \\
\hline $\begin{array}{l}\text {-It should exist in inner bound loop } \\
\text { of CAD model. } \\
\text {-It should have two edges. } \\
\text { - All the edges should be curved line. } \\
\text { - All the angles should be equal } \\
\text { radius. } \\
\text { - Angle of each curve is } 180 \mathrm{deg} \text {. }\end{array}$ & \\
\hline $\begin{array}{l}\text {-It should exist in inner bound loop } \\
\text { of CAD model. } \\
\text {-It should have eight edges. } \\
\text {-Four edge are straight line and four } \\
\text { is curved line. } \\
\text { - Length of straight line is equal, and } \\
\text { radius of curve line is equal. } \\
\text { - Angle of curve is } 90 \text { deg. }\end{array}$ & \\
\hline $\begin{array}{l}\text {-It should exist in inner bound loop } \\
\text { of CAD model. } \\
\text {-It should have four edges. } \\
\text { - Two edge are straight line, and two } \\
\text { edge is curved line. } \\
\text { - Length of straight line is equal. } \\
\text { - Angle of curve is } 180 \text { deg. }\end{array}$ & \\
\hline $\begin{array}{l}\text {-It should exist in inner bound loop } \\
\text { of CAD model. } \\
\text {-It should have eight edges. } \\
\text {-Four edge are straight line and four } \\
\text { is curved line. } \\
\text { - Length of straight line is equal, and } \\
\text { radius of curve line is equal. } \\
\text { - Angle of curve is } 90 \text { deg. }\end{array}$ & \\
\hline
\end{tabular}

Table 2. Conditions for feature recognition (Deep Drawing feature)

\begin{tabular}{|l|l|}
\hline IF & Then \\
-It should have three faces. \\
- One face is cylindrical face. \\
-One face is flat face. \\
- One face is torus face. \\
-It should have 17 faces. \\
-Eight faces are cylindrical face. \\
- Five face are flat face. \\
-Four face are torus face.
\end{tabular}

\section{INTEGRATION FEATURES WITH DIE DESIGN}

The sheet metal features after recognition are stored in the module to find edge connections to represent the shape of the feature. The edges surrounding the $2 \mathrm{D}$ features in case of punching features are stored in the routine. It retrieves once again to get the punch shape in one direction and retrieve once again to get the die shape in the opposite direction. As the sheet metal have 2 sides and the thickness, the punch has contact with one side of the sheet and the die will contact other side of the sheet. In case of the cupping features, features are decomposed to different faces.

The inner face of the cup will be in conjunction with the drawing punch, and the outer face of the cup will be in conjunction with the die. Figure 5, illustrated the controlling parameters of cupping and drawing shapes, such as; the inner face, the outer face, the inner radius face, etc. Figure 6 illustrated this relation between the part features and the adjacent die surfaces. The concept of die design depends first on the relation between part and its adjacent strategic parts such as punch, die and blank holder if exist. In this parametric relation, the punch and die sizes increase as the part size increase and vice-versa [8]. The new punch and die sizes and dimension consider as the references to build of remaining die components, as the size of the strategic parts affects the size and dimensions of the adjacent parts. Figure 7 , illustrate the components of the combination cupping and punching die main components. There are many shapes of typical cupping and punching dies, as the punched holes could be in bottom or in walls or in flanges. These shapes could be found in [2].

Finally, the Table 3, shows the Integration between part features, Process and die-type design. Table 3 shows the different type of cup shape sheet metal parts. The hole is punched into the cup shape part at different locations. These parts are taken from the MusumiTM catalogue. Parts shown in Table 3 is divided into groups, the single punched holes at the 
bottom of cup shape part and the multi punched holes in the bottom of the part. These types of parts are widely used in most of the domestic and industrial applications. The Table 3 divides the parts into its main features showing the tools which is necessary to produce these features. This action is also help to design internal part of the die, as it divides the design calculation based on the tools used to accomplish the sheet metal part process.

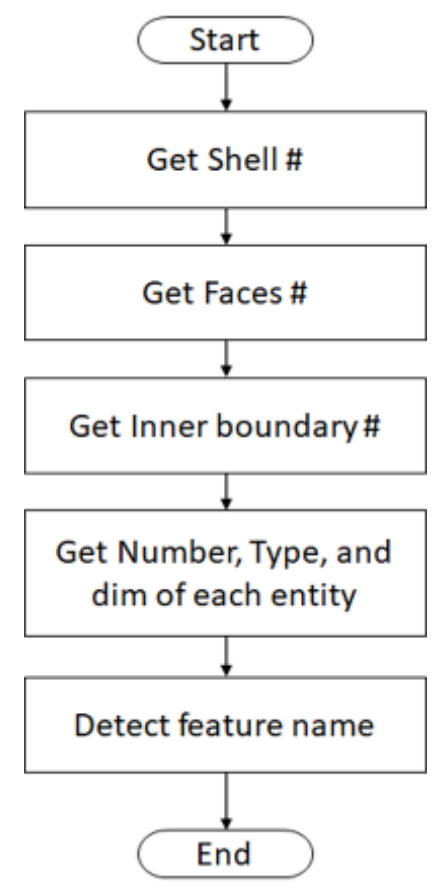

a)

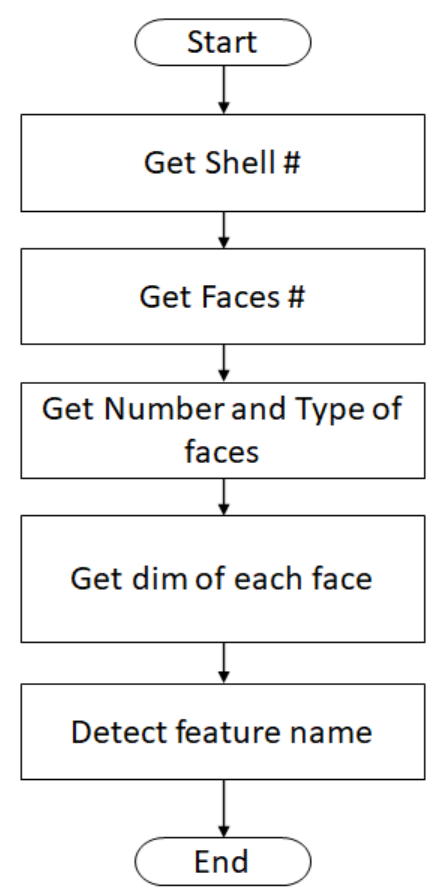

b)

Fig. 4. The proposed flowchart to recognize the features from punching and cupping sheet metal parts: a) punching flow chart; b) cupping flow chart

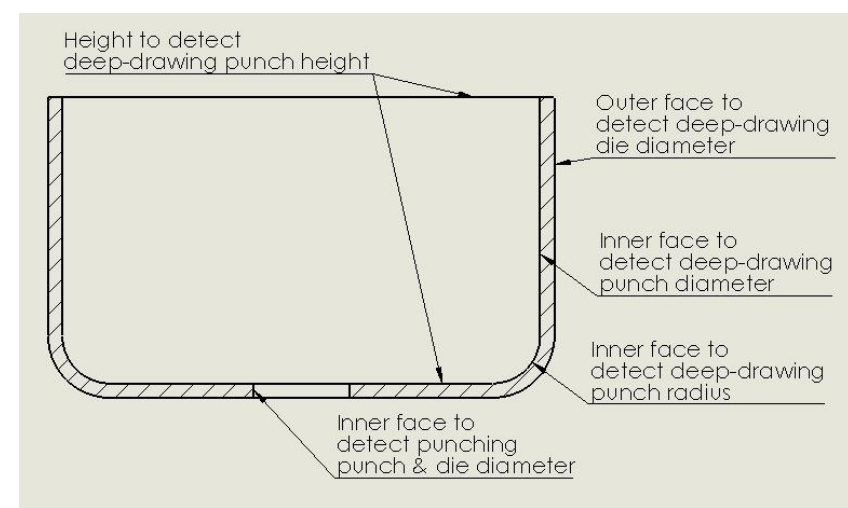

Fig. 5. The parameters related the cupping and drawing shapes

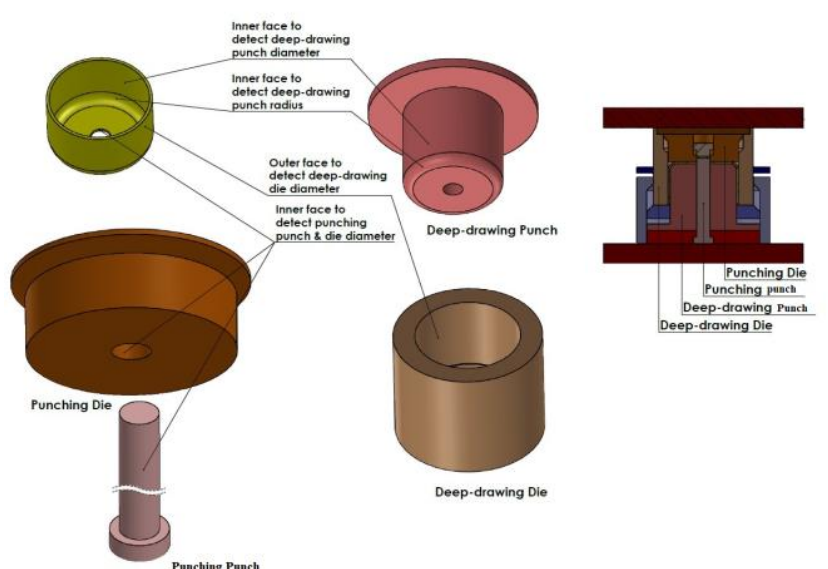

Fig. 6. The parameters affected the relation between the features and the die design

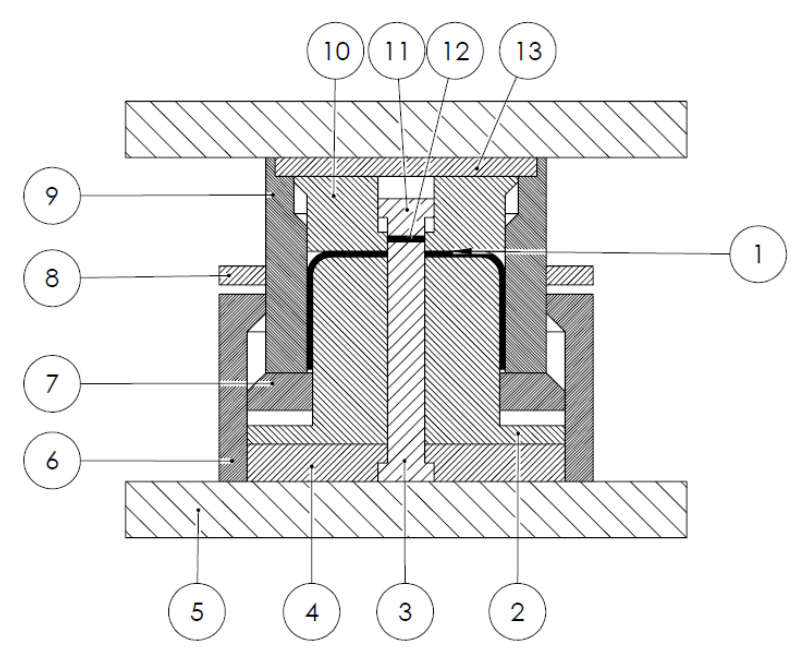

Fig. 7. The schematic drawing of cupping and punching typical die and its components; (1) Sheet Metal Part, (2) deep drawing punch, (3) punching punch, (4) Thrust plate, (5) Lower plate, (6) die holder, (7) plate, (8) blank holder plate, (9) deep drawing die, (10) punch die, 11) plate, (12) scrape, (13) thrust plate

\section{CONCLUSIONS}

In this work, an integrated computer system has been developed to identify sheet metal features and use these features for design and manufacturing of suitable sheet metal die. The system is developed using Visual basic 
programming language and integrated with Solidwork modeling software. Notable features of the proposed system are its low cost of implementation and drastically die component design time from hours to minutes. As developed system starts design the die components automatically with any help from expert die designer after recognizing the features of the sheet metal parts. Hence, the system is independent on skill and experience of domain experts. Therefore, it is consistent and less error prone.
The developed system can be used for manufacturability check, cost estimation etc. of sheet metal parts. The system works well for all types of features contained in the MusumiTM catalog and for different sheet metal industries. The proposed approached can be extended to define new types of sheet metal features and use this information for design suitable type of die to manufacture the sheet metal parts.

Table 3. Integration between part features, Process and die-type design

\begin{tabular}{|c|c|c|c|c|c|}
\hline $\begin{array}{c}\text { Part } \\
\text { geometry }\end{array}$ & $\begin{array}{c}\text { Feature } \\
\text { recolonization } \\
\text { data }\end{array}$ & Die Type & $\begin{array}{l}\text { Piercing punch } \\
\text { shape }\end{array}$ & $\begin{array}{l}\text { Deep drawing } \\
\text { punch shape }\end{array}$ & Die \\
\hline \multicolumn{6}{|c|}{ For Single Punching Features } \\
\hline & $\begin{array}{l}\text { Cup diameter } \\
\text { Cup height } \\
\text { Radius } \\
\text { Hole } \\
\text { dimension }\end{array}$ & $\begin{array}{c}\text { Combination } \\
\text { dies. }\end{array}$ & & & \\
\hline & $\begin{array}{l}\text { Cup diameter } \\
\text { Cup height } \\
\text { Radius } \\
\text { Hole } \\
\text { dimension }\end{array}$ & $\begin{array}{c}\text { Combination } \\
\text { dies. }\end{array}$ & & & \\
\hline & $\begin{array}{l}\text { Cup diameter } \\
\text { Cup height } \\
\text { Radius } \\
\text { Hole } \\
\text { dimension }\end{array}$ & $\begin{array}{c}\text { Combination } \\
\text { dies. }\end{array}$ & & & \\
\hline & $\begin{array}{l}\text { Cup diameter } \\
\text { Cup height } \\
\text { Radius } \\
\text { Hole } \\
\text { dimension }\end{array}$ & $\begin{array}{c}\text { Combination } \\
\text { dies. }\end{array}$ & & & \\
\hline & $\begin{array}{l}\text { Cup diameter } \\
\text { Cup height } \\
\text { Radius } \\
\text { Hole } \\
\text { dimension }\end{array}$ & $\begin{array}{c}\text { Combination } \\
\text { dies. }\end{array}$ & & & \\
\hline \multicolumn{6}{|c|}{ For Combined Punching Features } \\
\hline & $\begin{array}{l}\text { Cup diameter } \\
\text { Cup height } \\
\text { Radius } \\
\text { Holes } \\
\text { dimension }\end{array}$ & $\begin{array}{c}\text { Combination } \\
\text { dies. }\end{array}$ & & & \\
\hline & $\begin{array}{l}\text { Cup } \\
\text { dimension } \\
\text { Cup height } \\
\text { Radius } \\
\text { Holes } \\
\text { dimension }\end{array}$ & $\begin{array}{c}\text { Combination } \\
\text { dies. }\end{array}$ & & & \\
\hline
\end{tabular}




\section{REFERENCES}

1. Naranje, V., Kumar, S., (2011). A KnowledgeBased System for Manufacturability Assessment of Deep Drawn Sheet Metal Parts, KEM 473, 749-756. https://doi.org/10.4028/www.scientific.net/kem.473.7 49

2. Vishal Naranje; Shailendra Kumar, (2014), An expert system for selection of process parameters and strip-layout design for production of deep drawn sheet metal parts, International Journal of Internet Manufacturing and Services, 3(3), 263 - 278

3. Naranje V.G., Hussein H.M.A., Kumar S., (2017), Computer aided system for parametric design of combination die, ICMIM 2017, IOP Conf. Series: Materials Science and Engineering, 244, 1-7.

4. Hussein H. M. A, Naranje V., Abdelzaher W., Ramadan A. A. A., (2021), Study of Expert System for Integrated Cupping and Punching Operation, 2021 International Conference on Computational Intelligence and Knowledge Economy (ICCIKE), 508-513, doi: 10.1109/ICCIKE51210.2021.9410760. 5. Salem H., Gupta R.K., Gürün H., Hussein H.M.A., (2020), An Approach to Optimum Classification and Recognition the Sheet Metal Features According to STEP 10303, ICMATSE, International Conferene on Advanced Materials Science \& Engineering and High Tech Device applications, 59-62.

6. Gupta R.K., Salem H., Hussein H.M.A., Salunkhe S., Ramadan A.A.A., (2021), Sheet Metal Feature Recognition using STEP: Database for Product Development, Journal of Advanced Manufacturing Systems, World Scientific Publishing Company.

7. Musumi, (2020), Catalouge for Punches and dies, https://us.misumi-

ec.com/vona2/maker/misumi/press/P0100000000/, 19.

8. Vishal Naranje, Shailendra Kumar, (2013), An intelligent CAD system for automatic modelling of deep drawing die, International Journal of Computer Applications in Technology, 48(4), 330 - 344.
Received: July 30, 2021 / Accepted: December 15, 2021

/ Paper available online: December 20, 2021 (C) International Journal of Modern Manufacturing Technologies. 